\title{
A Poset-Generalizability Method for Human Development Indicators
}

\author{
Flavio Comim ${ }^{1,2}$ (D)
}

Accepted: 10 June 2021 / Published online: 17 June 2021

(c) The Author(s) 2021, corrected publication July 2021

\begin{abstract}
The paper introduces a poset-generalizability perspective for analysing human development indicators. It suggests a new method for identifying admissibility of different informational spaces and criteria in human development analysis. From its inception, the Capability Approach has argued for informational pluralism in normative evaluations. But in practice, it has turned its back to other (non-capability) informational spaces for being imperfect, biased or incomplete and providing a mere evidential role in normative evaluations. This paper offers the construction of a proper method to overcome this shortcoming. It combines tools from poset analysis and generalizability theory to put forward a systematic categorization of cases with different informational spaces. It provides illustrations by using key informational spaces, namely, resources, rights, subjective well-being and capabilities. The offered method is simpler and more concrete than mere human development guidelines and at the same time it avoids results based on automatic calculations. The paper concludes with implications for human development policies and an agenda for further work.
\end{abstract}

Keywords Poset analysis · Human development indicators · Generalizability theory · Informational pluralism $\cdot$ Capability approach

\section{Introduction}

Human development is multidimensional; however quite often it is represented by composite indicators (CIs) that lump together incommensurable features of countries or individuals into a single representation of their development (Nussbaum, 1990; Sen, 2009; French et al, 2013). As much as the communication benefits of CIs are self-evident, elaborating these indicators entails a range of pragmatic choices that have been criticised for being extremely subjective, arbitrary, potentially misleading and prone to obscure essential information (Barclay et al, 2019; Cherchye et al, 2007; Fattore, 2016; Freudenberg, 2003; Saltelli, 2007). Recent alternatives, such as the 'trichotomic segmentation approach' (Smirlis, 2020), the 'data envelopment analysis' for corporate social performance (Aparicio \&

Flavio Comim

fvc1001@cam.ac.uk

1 IQS School of Management, Universitat Ramon Llull, Via Augusta 390, 08017 Barcelona, Spain

2 Land Economy, University of Cambridge, Cambridge, UK 
Kapelko, 2019), the 'multicriteria reference point scheme' (Ruiz et al, 2020) and 'Munzner's visualisation analysis' (Albo et al, 2019), among others, provide fruitful paths for overcoming the shortcomings of CIs. Yet, a key alternative, intrinsically linked to the formation of the Human Development Approach (HDA) remains little explored empirically by the literature, namely, the use of 'partially ordered set (poset) analysis'. The low popularity of this analysis is most remarkable, considering that one of the prominent founders of the human development perspective, Amartya Sen, has been arguing for the use of partial orderings for the last 50 years (Sen, 1970a, 1970b, 2017). Indeed, methodologically speaking the rankings produced by human development indicators are meant to be ordinal and comparative in nature (Comim, 2008).

The use of CIs combines two distinguishable but interrelated core methodological challenges, namely, the transformation of different attributes into a common metric and the generation of complete orderings. In their essence, complete orderings, which can be strict or not, are lists (of countries, individuals, etc.) where every pair of alternatives can be ranked against each other. That is, either an alternative $\mathrm{x}$ is better than an alternative $\mathrm{y}$, or $\mathrm{x}$ is equal to $\mathrm{y}$ or $\mathrm{x}$ is worse than $\mathrm{y}$. For the overall majority of CIs, commensurability leads to complete orderings (Yang, 2014). But what happens if the dimensions of a CI or the use of different CIs do not provide a coherent picture? What can be done when different realities provide a conflicting picture? How to solve the very demanding claims imposed by full comparability of CIs?

One alternative is to replace the popular use of complete orderings by the use of partial orderings (Bruggemann \& Patil, 2011; Fattore and Bruggemann, 2017; Fattore et al., 2012). Somehow complete orderings represent an unnatural state of affairs because there are many elements in development and in life that are incommensurable and that produce ambiguities that scholars, as well as the general public, choose to ignore because they are difficult to handle. Altogether, we could argue that mathematically and empirically speaking, complete orderings are a particular case of partial orderings. Partial orderings -or partial rankings or partial comparability- consist in establishing minimum standards of comparability that can be asserted without contradiction of any other rankings. Here, the analytical possibility of incompleteness in ranking alternatives is not a handicap but, rather, freedom from what Sen has called 'the tyranny of required completeness' (Sen, 1985: 20-21). A pursuit of completeness that has had some disastrous consequences for development measurement, evaluation of social and economic achievements, policy-making and appraisal of justice.

Two issues are at stake here, namely, the impact of poset analysis on human development indicators and the implications of its use for Sen's Capability Approach (CA). The first issue is very simple, namely, what are the implications of producing poset rankings of human development indicators for development analysis? The second issue concerns the possibility of putting forward a unified account of Sen's Capability Approach (CA), based on its generalizability assumptions, that is relevant to human development policies. It suggests a new method for identifying admissibility of different informational spaces and criteria in human development analysis. From its inception, the CA has argued for informational pluralism in normative evaluations (Sen, 1980). But in practice, it has turned its back to other (non-capability) informational spaces for being imperfect, biased or incomplete and providing a mere evidential role in normative evaluations (Sen, 1999, 2002, 2009).

Given these two issues, the overall objective of this paper is to provide a poset analysis that fits a generalizable account of the CA. In so doing, we can move towards higher levels of informational pluralism, incorporating richer spaces, towards an analytical structure that avoids subjective, arbitrary and potential obscure choices of variables in 
the analysis of human development. Furthermore, with poset analysis we can examine in a systemic way different challenges faced by the CA such as the issue of 'adaptive preferences' or 'the conversion of resources into capabilities'. This paper contributes to the currently flourishing literature on poset analysis by providing a conceptual structure for using different informational spaces for assessing human development.

The paper is organised into six parts. The first part introduces poset analysis and its advantages over complete rankings. It emphasises the use of informational spaces, understood as a class of information articulated through common conceptual features. The second part presents the data used in the paper. The third part discusses the analytical framework of generalizability theory used to broaden the applicability of the CA. The fourth part examines the key results of combining poset rankings with generalizability tables. The fifth part discusses the main implications for human development policies. The final part offers suggestions for further work.

\section{Poset Analysis and Partial Rankings}

CIs and their complete orderings offer nothing less than a paradox: often the case for introducing a CI, based on informational pluralism and non-comparability of its components, results in a single measurement that hides key qualitative differences among dimensions and variables that would prevent sensible comparisons of countries or individuals. Moreover, it introduces a wide range of methodological choices related to scales, thresholds, implicit vs explicit weights, trade-offs, linear vs geometric means, choice of scales, among many others. All these issues emerge from a lack of proper recognition of incomparabilities regarding the components of the indicators and their respective attributes.

Before we introduce the tools of Poset analysis it is important that we revise some key definitions, in particular those used in social choice theory (Sen, 2017). An informational space is a class or category of information that refers to a common conceptual basis, such as utilities, rights, resources, among others. Within these spaces we find dimensions that represent a general aspect of an issue to be examined or measured. Variables provide a number or a quantity to characteristics of interest. Indicators contain a normative element, suggesting when certain values of given variables represent or not desirable situations. A partial ranking is an expression used in Sen's work to describe an ordering of alternatives that is not complete. An example might be useful to clarify these definitions. In the case of the Human Development Index (HDI) it works with two kinds of informational spaces, capabilities and resources. Its main dimensions are health and knowledge (related to capabilities) and standard of living (related to resources). The variables it uses are: life expectancy at birth (health), expected years of schooling and average years of schooling (education) and per capita gross national income (standard of living). In the case of the HDI no particular indicators are used because no thresholds are defined, so analysis is carried out by comparison among countries. In the field of explorative statistics it is common to refer to an evaluation space as a "mathematical entity that best reproduces the structure of the data and defines how they can be formally treated" (Fattore, 2016: 839) or to an informational base as a "set of attributes used in the data matrix" (Bruggemann \& Patil, 2011: 16). Here, the expression informational space refers to the conceptual categories of data as put forward by Sen (2017). 


\subsection{Representing Ordinal Data as Posets}

Let us assume, following Bruggemann and Patil (2011) and Fattore (2016), that we wish to assess the level of human development of a set $X$ of countries $a, b, c$ and $d$ such that $\mathrm{X}=\{\mathrm{a}, \mathrm{b}, \mathrm{c}, \mathrm{d}\}$. The countries are the 'objects' or 'the elements' of our finite set $\mathrm{X}$. Each country may be assessed according to a set Q (the space of measurement) that consist of data $\mathrm{q}_{1}, \mathrm{q}_{2}, \mathrm{q}_{3}$, etc. (in our case here we represent data by their general class of informational spaces, e.g., resources, subjective well-being, capabilities, etc., but it is usual to find in the literature reference to attributes as indicators). Assuming that all data are continuous (or at least ordinal), that is, that $\mathrm{Q} \subset \mathrm{R}^{\mathrm{m}}$ (the $\mathrm{m}$-dimensional space of real numbers that represent the different informational spaces), $\mathrm{q}(\mathrm{x})$ can represent the data row for $\mathrm{x}$ and $\mathrm{q}(\mathrm{y})$ for $\mathrm{y}$. In order to compare different objects we can use the symbol $\leq$ as a binary relation among different objects. The usual axioms that govern these relations are:

Reflexivity: $\mathrm{x} \in \mathrm{X}: \mathrm{x} \leq \mathrm{x}$ (an object can be compared with itself).

Anti-symmetry: $x \leq y, y \leq x$ means that $y=x$.

Transitivity: $\mathrm{x} \leq \mathrm{y}$ and $\mathrm{y} \leq \mathrm{z}$ implies that $\mathrm{x} \leq \mathrm{z}$ (this guarantees that objects can be at least ordinal scaled).

Whenever $\mathrm{x} \leq \mathrm{y}$ or $\mathrm{y} \leq \mathrm{x}$ we can say that $\mathrm{x}$ and $\mathrm{y}$ are comparable; but when this is not the case they are said to be incomparable (written $x \| y$ ). Following Fattore et al. (2012) we define a chain or a linear order as a partial order $\mathrm{P}$ where any two elements are comparable and an antichain when they are not. When all attributes are comparable, we have the particular case of a complete order such that all objects $\mathrm{x} \in \mathrm{X}$ can be arranged in a simple sequence, as it happens in CI, such that $\mathrm{x}_{1}<\mathrm{x}_{2}<\ldots<\mathrm{x}_{\mathrm{n}}$.

In development, the large majority of variables has an ordering with clear meaning, such as between higher vs lower infant mortality rates or between higher $v s$ lower average years of study. But not all of them. Some variables focusing on the nature of political institutions (e.g. proportional or majoritarian representation) do not offer an unambiguous criterion for ranking development. In most cases we say that:

$$
\mathrm{x} \leq \mathrm{y}, \quad \text { if and only if, } \mathrm{q}(\mathrm{x}) \leq \mathrm{q}(\mathrm{y})
$$

Of course, the interesting situation in the case of multidimensional indicators is when we have vectors of attributes that are composed of different (often incommensurable) characteristics. In the literature this corresponds to a move from ordering elements to ordering profiles, defined as sequences of scores (a vector of observed values) according to certain dominance criterion. Following Fattore (2016), let $\mathrm{V}=\left(\mathrm{v}_{1}, \ldots, \mathrm{v}_{\mathrm{k}}\right)$ be a set of $\mathrm{k}$ ordinal data (that can be called attributes or in our case can reflect variables that represent different informational spaces). Thus, sequences of scores on $\mathrm{v}_{1}, \ldots, \mathrm{v}_{\mathrm{k}}$ can represent achievement profiles, denoted as $\mathrm{p}=\left(\mathrm{p}_{1}, \ldots, \mathrm{p}_{\mathrm{k}}\right)$ or $\mathrm{q}=\left(\mathrm{q}_{1}, \ldots . \mathrm{q}_{\mathrm{k}}\right)$, constituting a set of achievement profiles by $\Pi$ with the scales of different number of degrees equal to $\mathrm{m}_{1} \mathrm{x} \ldots . \mathrm{x} \mathrm{m}_{\mathrm{k}}$. A partial order $\leq$ (in bold) would then state that a profile $q$ would be equal or worse than profile $p$, such that:

$$
\mathrm{q} \leq \mathrm{p}, \Leftrightarrow \mathrm{q}_{\mathrm{i}} \leq \mathrm{p}_{\mathrm{i}}, \quad \forall \mathrm{i}=1, \ldots, \mathrm{k}
$$

All chains will have a length provided by the number of elements that they have. They will also have a height defined by the number of elements of the longest chain. The number of elements of the largest antichains is defined as the width of the poset. Posets are then composed by chains and antichains that can be visually represented by diagrams called 
after H. Hasse. Several Hasse diagrams have different heights and widths, which motivates to introduce the term shape. A very simple Hasse diagram is represented by Fig. 1.

A Hasse diagram is a representation of a poset that combines all the comparabilities and incomparabilities observed in the poset (Caperna \& Boccuzzo, 2018). Objects are connected when they are comparable and not connected when they are incomparable. A chain is characterised by a sequence, a linearly ordered subset of the poset, such as $\mathrm{s}<\mathrm{w}<<\mathrm{y}<\mathrm{x}$ or a subset containing 2 or 3 elements only. Thus, if elements are linked, they are comparable by transitivity. An antichain is given by elements that cannot be compared, such as y and $\mathrm{z}$. In the example above, the chain would give the height of the poset as 4 and the antichain the width of the poset as 2 . We can understand the width of the poset as an expression of the level of incomparability among different attributes. Visually we can see that elements that are not connected in the diagram are not comparable. CIs tend to ignore these regions of ambiguity in their process of aggregation and in so doing eliminate the truly multidimensional nature of the phenomena that they aim to describe. In the case of complex Hasse diagrams it is possible to anchor the analysis of posets on particular elements and investigate its successors (downsets) and its predecessors (upsets).

\subsection{The Shapes of Posets}

It is important to note that not all attributes have the same power (influence) in organising poset objects. Some are more dominant, that is, more influential, than others due to their different capacity for discriminating among different elements of posets. For this reason, it is interesting to observe the shape of Hasse diagrams as produced by the combination of different attributes. It depends not just upon height and width of the posets but upon the network of relations among the objects (it is possible to have two different posets with the same height and width but with very different structures). For instance, the addition of one attribute can significantly increase the degree of incomparability in a given poset, enlarging

Fig. 1 An example of a Hasse diagram. Source: Bruggemann and Patil (2011). See also Caperna and Boccuzzo (2018) and Alaimo et al. (2020) for different illustrations of a Hasse diagram

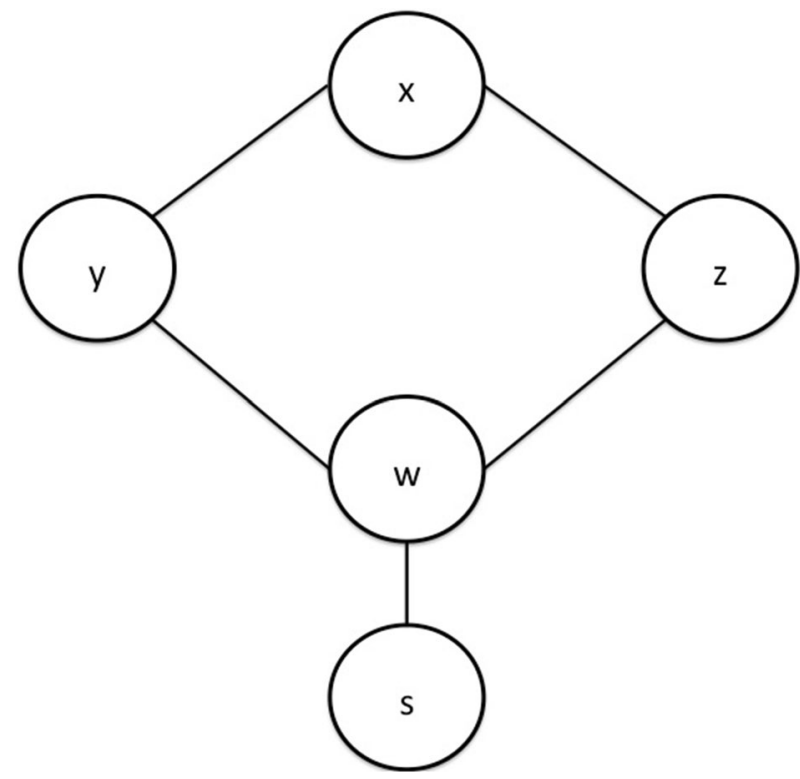


its width. By visualising a Hasse diagram we can assess whether the degree of incomparabilities is constant, increasing or decreasing with different levels. The point is that certain expansions of the informational bases of evaluations might produce posets with a lower or higher number of incomparabilities. It is thus possible to observe the responses of posets to changes in informational bases.

Posets are less demanding than CIs in informational terms. They avoid arbitrary methodological choices in the elaboration of CIs related to scales, thresholds, weights, etc. (in poverty assessments, posets are endowed with an antichain identifying poor profiles in a natural way, see Fattore, 2016). They are also metric-free and parametric free (Annoni \& Bruggemann, 2009). They allow us to see with more clarity the non-aggregative nature of the phenomena at hand (Fattore, 2008). They are more suitable to a world where partial comparability is the rule and the situations of full comparability and total non-comparability are exceptions. Moreover, the possibility of developing an informational analysis according to the type of informational basis used to carry out evaluations makes possible a systemic use of richer informational criteria. In other words, informational pluralism needs analytical tools such as poset analysis to overcome its own subjectivity and arbitrariness. Finally, it is worth mentioning that the use of poset analysis avoids reliance on a fixed set of attributes and the commitment to generate complete rankings based on arbitrary features. This can promote 'reasoned scrutiny' and public reason, key ingredients of the human development approach that have been consistently ignored by academia and policy-makers.

\section{Data}

The Human Development Approach supports the use of a wide variety of types of data following the principle of informational pluralism. However, this is often pursued by focusing on the association between capabilities and a particular informational space such as resources (Lavagnini \& Mennella, 2016; Rosano et al., 2009), subjective data (Anand et al., 2009; Kinghorn et al., 2015) and human rights (Burchardt \& Vizard, 2014; Fukuda-Parr, 2011), among others. In order to demonstrate how poset analysis can assist in tackling at the same time all these different informational spaces, selected data must satisfy two core criteria. First, it should represent the most characteristic informational spaces found in the literature of human development and the capability approach. Secondly, it should be easily available at Human Development Reports. Following these criteria, four kinds of key informational spaces or bases (IBs) were selected, namely:

1. Resources ( $r$ ) that potentially can be monetary or non-monetary

2. Subjective well-being ( $s w b)$ conveyed through personal opinions or views, pleasures, desires, desire fulfilment, choices

3. Rights ( $h r)$ that can be abstract or concrete, displayed as general or human rights

4. Capabilities (c) basic (mostly related to poverty) or non-basic

Although Sen (1970a, 1970b, 2017) does not distinguish empirically between informational spaces or informational bases, it is important to make this distinction here to avoid confusion. We shall call an informational space that kind of information that refers to a homogeneous category of data influenced by certain conceptual classifications, such as, e.g., rights, primary goods or capabilities. All information about rights used here refers to covenants and conventions and to nothing else. However, within rights we could 
characterise different attributes as far as some rights concern more children's rights, others women's rights, and so on. Given that the objective of this paper is to illustrate pluralism among different informational spaces, we treat each space as if it were homogeneous. On the other hand, we should also recognise that within a single informational space we can also find plurality at the level of dimensions, variables and indicators. A CI could then be plural because it combines variables that refer to resources or capabilities and because within each of these informational spaces it includes variables that are plural, e.g. because they refer to resources as financial resources, natural resources, human resources, etc. Whereas there are two distinguished levels of pluralism related to CIs, chosen data here focuses on the pluralism of informational spaces.

Poset analysis allows us to work with all these informational spaces at the same time, examining in a systematic way their tensions, conflicts and contradictions. This represents a significant practical step forward in using the CA for analysing human development data. As much as Sen $(1985,2009)$ is correct in rejecting automatic criteria for normative evaluations, there are very few tools available in the CA that can provide methodological help for handling informational pluralism. Poset analysis can provide fruitful results in combining different informational spaces and as such can even be used with capabilities lists, such as those introduced by Nussbaum $(2011,2018)$. The lists are structured around ten central capabilities that can be more concretely defined by different societies. They include human entitlements related to life, bodily health, bodily integrity, senses, imagination and thought, emotions, practical reason, affiliation, other species, play and control over one's environment.

Table 1 presents data chosen from Human Development Reports to represent each of these categories of informational spaces in the poset analysis. While most of them are straightforward, it is important to clarify how the information about fundamental human rights displayed in the 2019 Human Development Report (Table 15 of the report) was transformed into an indicator. Human rights are represented by 11 international conventions and covenants about elimination of racial discrimination, promotion of civil and political rights, elimination of discrimination against women, promotion of children's rights, etc. For which country it was calculated the number of days between their national ratification and the dates of entry of international conventions and covenants into force. The rationale behind this calculation is that countries that are more considerate of these rights were quicker in nationally ratifying them (although there are exceptions of this norm because of historical circumstances). Results were then aggregated and normalised. Since

Table 1 Different Informational Bases

\begin{tabular}{|c|c|c|}
\hline Informational basis & Indicator & Source \\
\hline Resources & Gross Domestic Product per capita (GDPpc) & 2019 HDR, Table 10 \\
\hline Subjective well-being & $\begin{array}{l}\text { Perceptions of individual well-being: education quality, } \\
\text { health care quality and standard of living }\end{array}$ & 2018 HDR, Table 14 \\
\hline Rights & $\begin{array}{l}\text { Composite indicator prepared based on the normalised } \\
\text { distance between the dates of national ratification and dates } \\
\text { of entry into international force of } 11 \text { international conven- } \\
\text { tions and covenants }\end{array}$ & 2019 HDR, Table 15 \\
\hline Capabilities & $\begin{array}{l}\text { Human Development Index, considered here as a capability } \\
\text { indicator }\end{array}$ & 2019 HDR, Table 1 \\
\hline
\end{tabular}


the focus here is on how different informational spaces are analysed by using poset, no additional attention was given to the internal pluralism of the human rights indicator.

For representing the informational space of capabilities we need a proxy. The best proxy, as argued by the 2010 and 2020 Human Development Reports, is the Human Development Index (HDI), understood as an indicator of capabilities that people can enjoy in different countries. We can then see, in particular, life expectancy at birth, expected years of schooling and average years of schooling as substantive freedoms that people might enjoy for a better life (Sen, 1999, 2017).

\section{Analytical Framework: Generalizability Theory}

Resources, such as GDPpc or Rawlsian primary goods (goods of general purpose according to Rawls's Theory of Justice), are imperfect indicators of human well-being because heterogeneous individuals might convert similar resources into distinct actual achievements according to their different possibilities. For this (conceptual) reason, resources as an IB, are not enough for a complete description of a country's or a person's advantage. On the other hand, it would be simply wrong to ignore the possibilities opened by resources in furthering one's development. Similarly, subjective information might present several biases and distortions, such as adaptive preferences. But we should not forget that being happy or satisfied about something is an important achievement in itself and that despite its biases, subjective information can provide evidential role in welfare evaluations. On their turn, human rights can be formally recognised without any guarantees that they will lead to their intended results. Not to mention that human rights should not be seen as absolute or lexicographic imperatives because they matter alongside other concerns (Sen, 2009).

The point is that the information that particular IBs provide cannot be generalised to other informational spaces. This means that informational pluralism is necessary for comprehensive assessments (Sen, 1980, 1992, 1999, 2017). However, this is ultimately a question to be empirically rather than theoretically settled. For this reason, the generalizability hypothesis behind the use of different IB should also be assessed empirically, with the identification and quantification of inconsistencies and tensions arising from the combination of different informational spaces. In other words, different informational spaces should not be discarded from evaluations as a matter of doctrine but rather being empirically investigated.

Key insights from Generalizability Theory (GT), as developed by Cronback et al. (1972) and extended by Brennan (2001) can be applied here. Coherent with Sen's (1977) informational admissibility criterion, we can call different informational spaces of 'universes of admissible information'. Within this context, the generalizability format will be defined by combinations of different universes of admissible information in which they are 'crossed with'. Using the IBs described above, we would have that conditions of generalizability will produce a 'crossed with' of $\mathrm{r} \otimes \mathrm{swb} \otimes \mathrm{hr} \otimes \mathrm{c}$. Following Sen's approach, the cross operator means that we should check conceptually the comparabilities and incomparabilities among different attributes from distinct informational spaces. But the use of informational spaces can be different to each case, because context matters for human development and no mechanical or automatic algorithm should be used for normative evaluations without taking into account the particularities of certain situations. Quite often the best combination of informational spaces can be defined by those development aspects that are 'morally salient' (as defined by Herman, 2007). The use of posets can help us in identifying the 
'generalizability power' of different spaces (and their corresponding variables and indicators) in ranking countries or individuals. They can also highlight the importance of key inconsistencies and conflicts among them Thus, any observable measurement can be represented by some possible combinations of the different informational spaces that might be considered relevant to the situation. In our case here, we work with key informational spaces as illustrations of the potential of poset analysis.

In the case of having four groups of admissible observations, $\mathrm{Xr}$ (resources), Xswb (subjective well-being), Xhr (human rights), Xc (capabilities), when crossed with are $\mathrm{Xr} \otimes \mathrm{Xswb} \otimes \mathrm{Xhr} \otimes \mathrm{Xc}$, resulting in possible combinations of a country (or a person's) advantage as:

$$
\mathrm{ADV}=\mathrm{Xr}+\mathrm{Xhr}+\mathrm{Xswb}+\mathrm{Xc}+\mathrm{Xr} \otimes \mathrm{r}+\mathrm{Xr} \otimes \mathrm{swb}+\mathrm{Xr} \otimes \mathrm{c}+\mathrm{Xhr} \otimes \mathrm{swb}+\mathrm{Xhr} \otimes \mathrm{c}+\mathrm{Xswb} \otimes \mathrm{c}
$$

These combinations can be typified into a generalizability table, such as Table 2, that represents all relevant informational spaces alongside the situations that they characterise. Several other combinations are logically possible according to the chosen mix of informational spaces. In particular, given 4 spaces (that could be seen through 4 separate indicators, one for each category of information) we could have $2^{\mathrm{m}}=16$ different possible combinations. However, not all combinations would be meaningful from a capability perspective. For this reason, we focused here on 7 cases that allow us to explore all logical situations examined from a capability perspective. We use two codes only: (A) for 'apply' and (NA) for 'does not apply'. They refer to when the use of a particular informational space, through a set of variables and indicators, suggests or not an advantage for a particular individual or country. Given that we have carried out a poset analysis for countries we will refer to countries as our main unit of interest.

Situation (1): it is when a country has enough resources to be in a favourable position and all other variables reinforce this assessment. In this case, all different spaces can be generalised, once they provide the same qualitative information about the advantage position of people living in a certain country.

Situation (2): it is when a country does not score well in terms of resources, rights or capabilities but subjectively people in that country evaluate that they are well. Happiness studies would usually assume that subjective information can be generalised as an indicator of a country's advantage. But if this information conflicts with information from other IBs, one should acknowledge the potential problem of adaptive preferences (when people adapt to a bad situation in order to psychologically survive to it).

Table 2 Generalizability table for four informational spaces

\begin{tabular}{llllll}
\hline Cases & Resources & Rights & SWB & Capabilities & ADVANTAGE \\
\hline$(1)$ & A & A & A & A & Full advantage \\
$(2)$ & NA & NA & A & NA & Adaptive Preferences \\
$(3)$ & A & NA & A & NA & Violation of minimal liberty \\
$(4)$ & A & NA & NA & NA & Failure of conversion of resources \\
$(5)$ & NA & A & NA & NA & Empty rights \\
$(6)$ & NA & NA & NA & A & Resilience \\
$(7)$ & NA & NA & NA & NA & Full disadvantage \\
\hline
\end{tabular}


Situation (3): it is when a country has enough resources to be in a favourable position and its people are relatively happy about their achievements, despite being deprived of their rights and valued capabilities. This seems to be an extension of the case previously described by Sen (1970a, 1970b) as the impossibility of a Paretian Liberal, where subjective evaluations (in Sen's article, expressed by people's majority vote) end up violating minimal liberty rights of a minority.

Situation (4): it is when a country has enough resources but evidence from other informational spaces suggests that people are unhappy about their situation and their suffer rights \& capabilities deprivations. This would be the situation of rich countries, where their population do not benefit from basic freedoms, such as political liberties, and are subjectively aware of these constraints.

Situation (5): it is when rights are formally acknowledged in a country (e.g. contemplated by laws) but this is not translated into corresponding resources, subjective satisfaction and capabilities. As a result, laws might not be implemented for lack of means, people might not have their freedoms and capabilities expanded and might become very cynical about the existence of these rights only on paper.

Situation (6): it is when a country is able to achieve certain valuable capabilities despite lack of means such as resources or rights. It is interesting to note that people might not fully appreciate, or even be negative, about the achieved functionings and capabilities. This could be the situation of a poor country that achieves lower infant mortality rates despite unfavourable economic conditions, human rights violations and a context where its population is unaware or unappreciative of the achievement. Although there is no well-established label in the human development literature for this outcome, we can call it 'resilience' to illustrate an unlikely positive outcome given the other negative parameters.

Situation (7): it is when a country does not have the resources, capabilities or rights and its population is aware of these multiple failures. This is a situation, for instance, that can be prevalent in many development countries struggling to fight against poverty but without the means (economic and legal) to achieve results that never come and its population is aware of these failures.

It is important to note that ADV (advantage) represents i) conceptually, an all-encompassing construct for Sen that can be defined as a union of all informational spaces and ii) empirically, a subset resulting from the intersection of the crossing operator with all these informational spaces. Altogether, these cases provide a systematic way in which we can look for evaluations where we can empirically verify how different informational spaces conflict or are coherent with each other. Thus, issues that were previously seen in a separated (and conceptual) way can be integrated as part of an evidence-based strategy of working with concrete contexts and practical empirical evaluation challenges.

\section{Results}

Composite indicators tend to ignore incomparabilities among their different dimensions and variables. As a result, they provide complete rankings that are to a certain extent artificial. Their dimensions can belong to common categories of informational spaces. They can all refer to resources, capabilities, rights or even to subjective information, as it is the case of the 'Ranking of Happiness' (Helliwell et al., 2020). Or they can be mixed such as Robeco's Country Sustainability Ranking or the Index of Sustainable Economic Welfare. 
It is to be expected that sustainability indicators, having to combine social, economic and environmental dimensions will be more affected by incomparabilities.

We put together an index for 154 countries that combine four key IBs, namely, resources, swb, rights and capabilities, all extracted from HDRs. The index does not have a name, because it is not important per se, but rather for the relations among its dimensions. For this reason, we have not used average ranks of countries' profiles to produce a synthetic measure of their human development (Bruggemann \& Carlsen, 2011). Instead, the focus was on typifying the incomparabilities emerging from an analysis of the overall ranking.

The main results can be seen on the Hasse diagram, displayed at Fig. 2, produced with the use of the software PyHasse (www.pyhasse.org). The first, and most striking, result is that there are 11 levels of rankings organised according to the incomparabilities among different IBs. This sharply contrasts with UNDP's classification of countries into four key groups (very high human development, high human development, medium human development and low human development) as if we had only four categories of ranking among countries. The result is clear: if we wish to take into account an informationally richer perspective of human development, we should be prepared to consider that the current classification of countries dismisses a more complex picture emerging from the consideration of incomparabilities between different development parameters used to rank countries.

In addition, we can observe that the influence of these incomparabilities is not homogeneous along the diagram. With larger antichains at the top and the middle of the poset, there is a maximum width of 27 countries in the middle and of 20 countries at the top. However, the incomparabilities seem to be less of a problem in the case of the worst ranked countries. Whereas some of these results at the top are predictable for rich countries such as Norway, Austria, Germany, Denmark, France, Luxemburg, etc., they might be

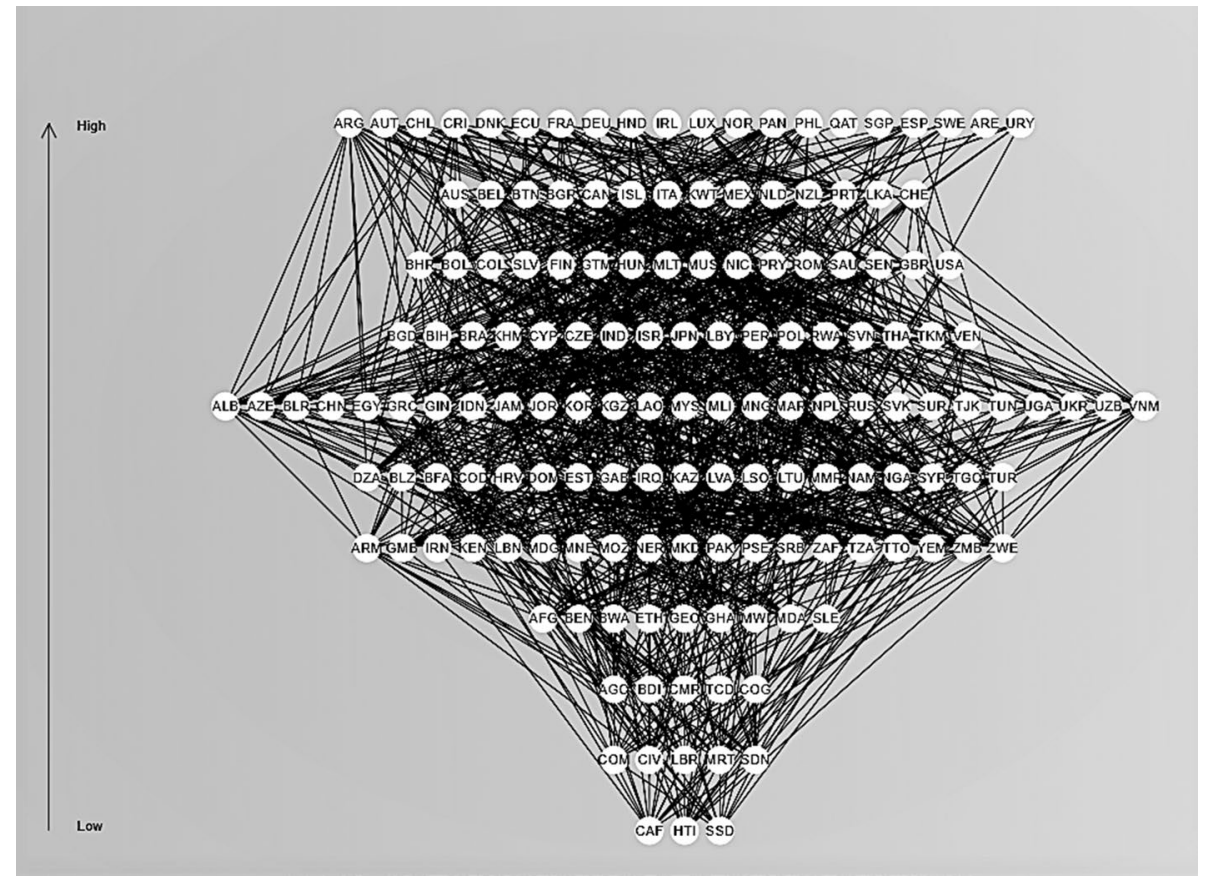

Fig. 2 Hasse diagram of Poset analysis on resources, swb, rights and capabilities 
surprising, or counter-intuitive for poorer countries such as Argentina, Chile, Costa Rica and Ecuador, among others. This happens because one of the key dimensions (represented here by different IBs) is more decisive than others in generating incomparabilities between different countries, as discussed below.

A clearer illustration of these rankings is provided by an analysis of individual downsets. They can be produced for any country and here, just to exemplify, are produced for Argentina, Austria and France, displayed at Fig. 3 with 11 elements in their maximum of all maximal chains. We can see how the number of countries compared and their respective links for Argentina is lower than the density for Austria and France. When we analyse the particular case of Argentina, it becomes clear that it is at the top level of the ranking not because of its resource (GDPpc), or subjective well-being or capabilities (HDI), but because of its high rights indicator. The sensitivity of the poset in relation to different informational spaces (attributes) can be appreciated by their shape, as illustrated by Fig. 4, that presents four different combinations of posets without one of the IBs, so that we can see the impact of their respective influences by removing them from the general ranking.

The Hasse diagram (a) is generated by removing the dimension and IB of rights from the general ranking. As a result, the diagram is organised into 21 levels, suggesting a lower degree of incomparabilities (due to its lower widths) in comparison to the overall ranking of Fig. 2. A similar shape is produced by the Hasse diagram (c) when swb is removed from the general ranking. In any case, it has a height of 17 levels, lower than the one without rights but higher than the ones from other diagrams. Indeed, the shapes of the Hasse diagrams (b) that does not include resources and (c) that does not include capabilities (HDI) are very similar to the overall shape of the Hasse diagram of Fig. 2. This is to be expected because resources and capabilities are the highest correlated informational spaces (for our particular sample their coefficient of correlation is $r=0,77)$. It is therefore when we introduce the human rights indicator, that is moderately correlated with the capabilities $(r=0,19)$ but very little with resources $(r=-0,03)$ and swb $(r=-0,01)$ that these incommensurabilities come to the front.

These partial rankings are much more complex than the complete rankings presented by most development indicators. They provide a more accurate and precise picture of how countries relate to each other, given certain configurations of informational spaces. In particular, they show that the hypothesis that all countries are comparable is not universally applicable. Imposing full comparability when evidence is telling us otherwise can take us away from the more productive exercise of examining the nature of these incomparabilities.

A generalizability table, such as the one presented by Table 3, can further illustrate some of these complexities. Countries were arbitrarily selected here just to illustrate the concepts. The different cases, from (1) to (7) explore empirically how incomparabilities can be typified according to the main tenets of the HDA and the CA. At the extremes, (1) and (7), we find out situations of full advantage and full disadvantage. This is how we normally interpreted comparisons in CIs. But we can see in both cases, with illustrations from Norway vs Switzerland on one extreme and illustrations from Liberia and Gambia on the other, that these positions can be asserted under very restrictive conditions (of satisfying dominance in all IBs). The general instance seems to be made of different patterns of incomparabilities. Case (2) between Buthan vs Denmark shows a pattern where people in a country (in this case Buthan) have a higher level of subjective satisfaction not supported by evidence from other IBs. This case can be typified as a condition similar to adaptive preferences.

Case (3) also explores a conflict between different IBs, namely, between countries with a higher level of resources and subjective well-being that do not benefit from corresponding 


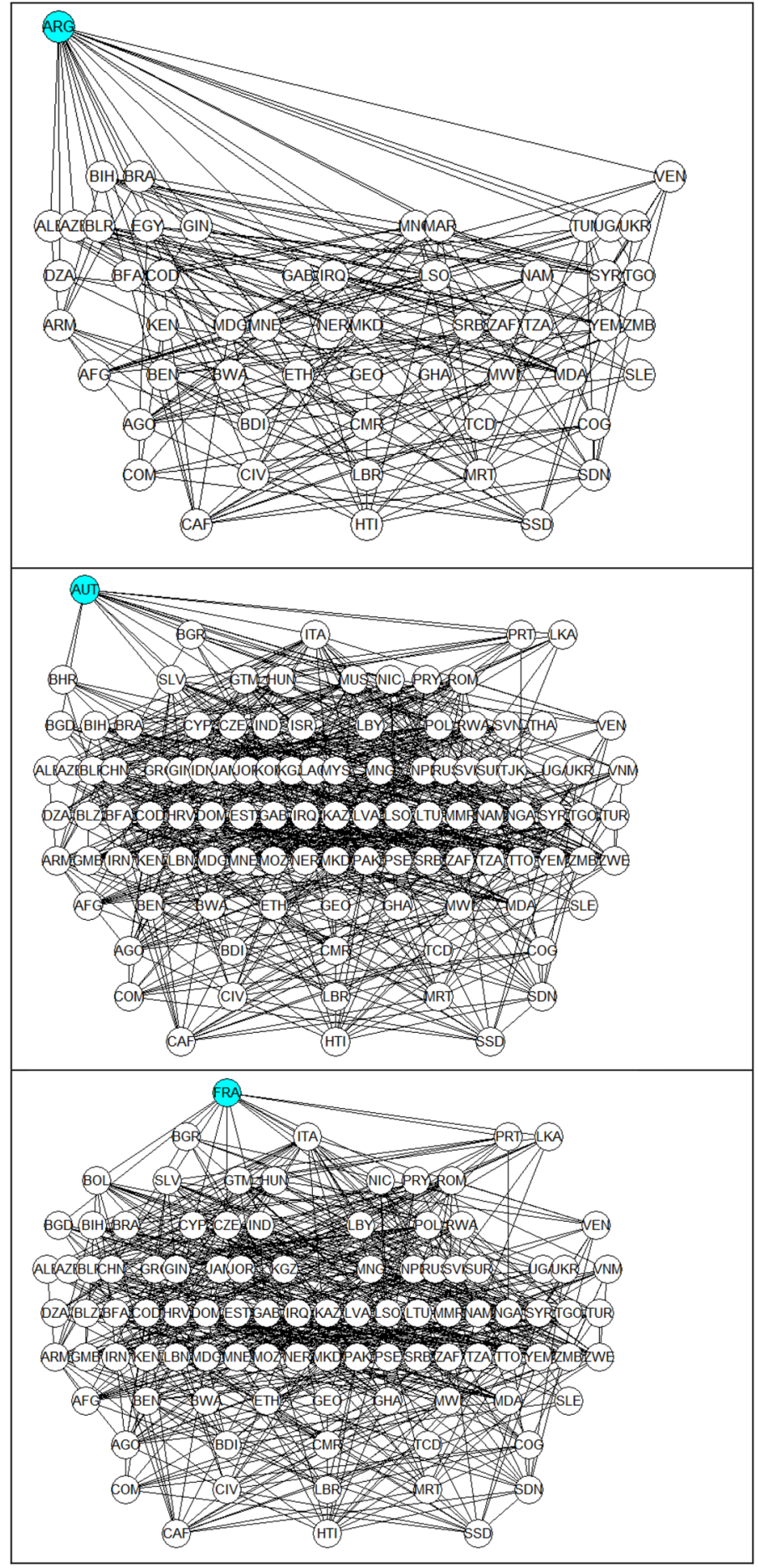

Fig. 3 Downsets for Argentina, Austria and France 


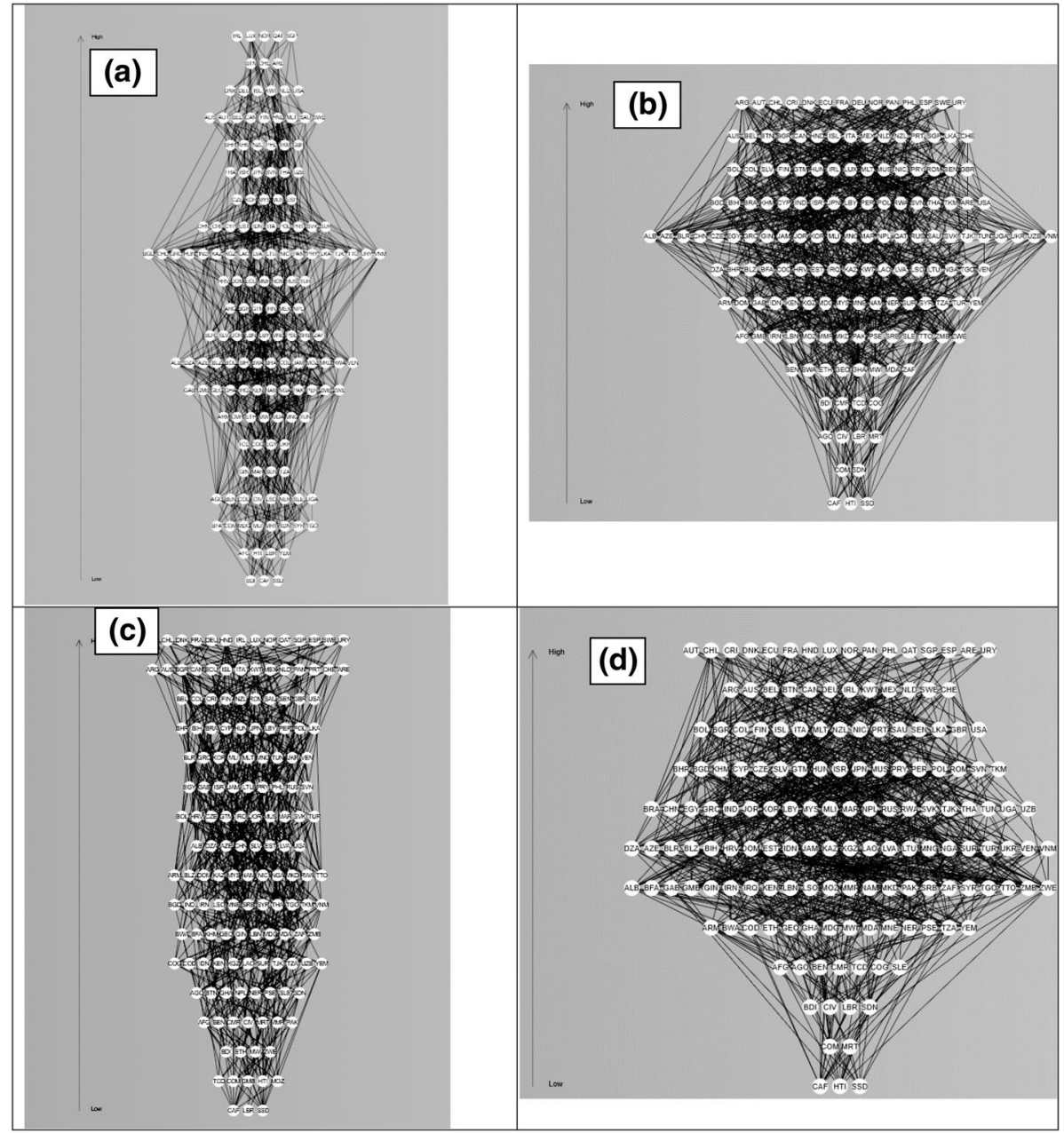

Fig. 4 Posets without rights (a), without resources (b), without swb (c) and without capabilities (d)

achievements in terms of rights and capabilities. This might refer, in the illustration between the United Arab Emirates vs the United States, to violation of minimum liberties (in this case represented by a low adherence to human rights conventions and covenants). Not that the US ranks very high in this particular rights dimension, but everything should be assessed in comparative terms. Case (3) is similar but different to case (4) where a country might be richer but unable to translate this relative abundance of resources into more rights, capabilities and subjective well-being for their population, as seems to be the case of Kuwait vis-à-vis the Netherlands. Because case (4) is not restricted to the rights issue, it can be typified as a general failure of conversion of resources into development dimensions.

It is interesting that countries can be in an opposite situation, such as case (5) where they formally recognise rights (and can actually be very quick in doing so) but do not follow this act with the necessary resources to produce changes in terms of capabilities or even subjective well-being. This seems to be the case of Senegal, with a higher rights IB 
Table 3 Generalizability Table for resources, rights, swb and capabilities

\begin{tabular}{lllllll}
\hline Cases & Resources (GDPpc) & Rights (RDI) & SWB & Capabilities (HDI) & Advantage \\
\hline$(1)$ & & & & & \\
NOR & 65.441 & 0.72 & 90.95 & 0.954 & Full advantage \\
CHE & 59.019 & 0.54 & 88.25 & 0.946 & \\
$(2)$ & & & & & \\
BTN & 9.348 & 0.27 & 89.29 & 0.617 & Adaptive Preferences \\
DNK & 47.673 & 0.74 & 87.37 & 0.93 & \\
$(3)$ & & & & & Violation of minimal liberty \\
ARE & 66.616 & 0.27 & 84.86 & 0.866 & \\
USA & 55.681 & 0.32 & 75.67 & 0.920 & Failure of conversion of resources \\
$(4)$ & & & & & \\
KWT & 65.515 & 0.55 & 73.13 & 0.808 & Empty rights \\
NLD & 49.803 & 0.64 & 87.21 & 0.933 & \\
$(5)$ & & & & & Resilience \\
SEN & 3.356 & 0.85 & 46.83 & 0.514 & \\
FRA & 39.555 & 0.79 & 74.56 & 0.891 & Full disadvantage \\
$(6)$ & & & & & \\
BLR & 17.742 & 0.68 & 46.38 & 0.817 & \\
ROM & 24.544 & 0.73 & 63.53 & 0.816 & & \\
$(7)$ & & & 39.94 & 0.465 & & \\
LBR & 1.161 & 0.37 & 58.86 & 0.466 & & \\
GMB & 1.517 & 0.44 & & & & \\
\hline & & & & & \\
\hline
\end{tabular}

than France, but lower performance in all other development measures. In this situation, rights are at best, empty promises. Finally, case (6) illustrates a logical possibility where, despite all the odds, a country manages to achieve a higher level of capabilities despite its lower resources, rights and subjective well-being. These cases are hard to find and here the comparison between Belarus and Romania provide one of the very few possible examples of this situation of resilience. Overall, these different cases provide an argument, based on partial rankings, for avoiding full comparability between the development positions of different countries.

\section{Discussion: Implications for Human Development Policies}

Poset applications are not new to natural sciences. They have been used in chemistry, environmental chemistry, hydrology, environmental health, biology and environmental sciences for some time (Bruggemann \& Patil, 2011). This could also be said of social sciences. But here we should contrast early studies such as Levy (1985) on crime indicators with a more contemporary poset literature championed by Fattore (2008) on poverty measures, Annoni and Bruggemann (2009) on perceived performance of public services, Fattore et al. (2012) on general well-being measurement, Fattore (2016) on multidimensional deprivation and Ip et al. (2016) on the evaluation of layman beliefs about diabetes. It is difficult to select a particular timeframe to disentangle the long-term evolution of this literature 
on social sciences from its recent expansion, but this fact should be acknowledged. Just to offer a flavour of the range of the recent poset applications we could mention: Hilckmann et al. (2017) on the links between political parties and sustainable development; Fattore and Arcagni (2018) on child well-being; Caperna and Boccuzzo (2018) on life-satisfaction; Di Brisco and Farina (2018) on gender inequality; Arcagni et al. (2019) on deprivation of migrants; Carlsen and Bruggemann (2019) on failed states; Ivaldi et al. (2020) on urban social deprivation and Alaimo et al. (2020) on sustainable development.

Reviewing this flourishing literature is beyond the scope of this paper. However, it is important to remark, in complement to the above mentioned contributions, that the analysis carried out in this paper uses poset analysis with insights from generalizability theory to examine the conceptual structure necessary for a systematic analysis of human development data. In particular, it tackles the issue of the inconsistencies among different informational bases (IBs) that are so characteristic of the capability literature. The categorisation and typification offered here allow the construction of a proper method using human development data that is simple and more concrete than mere guidelines and at the same time respectful to the core human development principle of avoiding normative judgements that are automatic and independent from the contexts in which they take place.

It is essential to acknowledge that some empirical results produced by the poset analyses with the corresponding illustrations from the generalizability table are contingent on the particular countries and indicators that compose the chosen informational bases. It is also interesting to note, when dealing with numerical data, that incomparabilities can be due to small differences in attribute values that may well be non-significant. In these cases, one might consider discretizing continuous variables to take into account very small differences. Nevertheless, the analytical results are established independently from the specific configuration of the different informational spaces. Moreover, it can be argued that their main implications for human development policies (HDPs) are:

1. The formulation of HDPs should be evidence-based and not exclusively dependent on a priori theoretical principles, as conceptually sound as they can be. The use of poset analysis with generalizability tables, presented here, can offer an alternative for systematically handling key IBs for human development. There are no reasons why HDPs should not try to avoid arbitrary ad hoc claims based on particular choices of informational spaces, as it seems to be the current standard in the literature;

2. HDPs should not be blindly informed by CIs because their rankings might hide incomparabilities and different sources of underdevelopment that might have distinct qualitative natures. The poset analyses carried out above illustrates how different countries (or regions, etc.) have idiosyncratic challenges, defined over particular informational spaces, that must be recognised in order to be more effectively addressed. Thus, for example, if one country is located at a lower level in a Hasse diagram because it suffers from a low human rights profile (comparatively to other countries), then, e.g. the promotion of higher economic growth does not seem the most efficient way to change the relative position of the country in the overall ranking of human development;

3. HDPs can rely on comparative analyses, as advocated by Sen $(2009,2017)$, but these comparisons should be made with great caution. Ranis and Stewart's (2010) suggestion to compare groups of countries according to their initial conditions is useful in order to avoid the usual mistakes of comparing countries with the fastest growth in HDI or the largest short-fall reduction. But the implication examined here goes beyond this general recommendation, alerting to the fact that comparisons should be pursued within 
particular comparative rankings, as we can see in Fig. 3 with the analysis of down sets to Argentina, Austria and France;

4. Generalizability tables do not have always to comprise the four IBs used here (resources, subjective well-being, human rights, capabilities). They provide a method to systematise human development data and as such can be fed and adapted according to the empirical specificities of the normative exercise at hand. However, the four IBs considered here have been extensively examined by the human development literature and it might be hard to ignore their substantive role in the promotion of HDPs;

5. The configuration of the different Hasse diagrams in Fig. 4, for distinct IBs, showed the importance of human rights indicators in the classification of countries. Given the fact that the rights IB is not much correlated with the other IBs, it has produced a higher number of incomparabilities that affect most the shape of the diagrams. This means that this IB has a key strategic role in structuring human development;

6. Open acknowledgement of the incomparabilities comprised by HDPs is essential for the promotion of public reason as the main engine of human development processes. For instance, if a given country cannot go up in a poset ranking because of a particular attribute, it is important that the civil society of that country discusses what are the causes of this undesirable state of affairs. This is not merely a technical issue, similar to point 2 above. It is a political issue, that might influence how the political ideology of a particular country is shaped by the information its citizens consume (Piketty, 2020);

Poset analysis can offer a systematic tool for handling incomparabilities in human development. As such, it can give a coherent empirical voice to several conceptual tenets of human development and the CA. By doing so, it can promote a level of consensus in operationalizing and implementing HDPs as we have not seen earlier in the history of development (Arndt, 1989; Gasper \& Gomez, 2014).

\section{Conclusions: An Agenda for Further Work}

Multidimensionality and composite indicators are incompatible bedfellows. Exalting multidimensionality and ignoring the incomparability of its dimensions (and variables) is, at best, a paradox and, at worst, a grave inconsistency. To move forward and take seriously the incomparabilities of human development indicators, it is necessary to consider alternative method, such as the use of partial orderings. Partial orderings are per se an invaluable tool to identify and organise incomparabilities emerging from the use of different informational bases, as the recent flourishing literature demonstrates. But posets can help us to advance much further. By connecting poset analysis with insights from generalizability theory, in particular the use of generalizability tables, we can start categorising and typifying conceptually where countries are in terms of their human development. This can potentially be applied to other units of analysis, meso or micro, such as families, schools, hospitals and individuals.

The particular choice of four key IBs in this paper derives from a vast capability literature that provides the theoretical foundation of the HDA. But this choice does not have to be sacrosanct. An agenda for further work should explore the contexts of new assessments with richer informational spaces, including other dimensions and variables that reflect appropriate ethical judgment and context-relevance. This can represent a step forward, not 
only empirically but also theoretically, allowing further analyses of the trade-offs, tensions and contradictions between different IBs in shaping human development policies.

Sen (1997) introduces a conceptual distinction between culmination and comprehensive outcomes. For him, culmination outcomes are measures of finalistic, ultimate results whereas comprehensive outcomes are measures of results including the processes through which these finalistic results happen. It is interesting to note that in this paper all key IBs were analysed as culmination outcomes. But they could be analysed also in terms of comprehensive outcomes, providing a much richer picture of how countries pursue certain policies that are not coherent with their stated human development objectives. For instance, if one way of increasing GDP or capabilities would be achieved by a weakening of democratic powers (as a process) then culmination outcomes could be increased but not necessarily comprehensive outcomes.

Finally, it should be mentioned that one of the key results of the present analysis refers to the sensibility of the overall Hasse diagram to the inclusion of the human rights IB. This suggests that distinct informational spaces might unveil different levels of structuring impacts produced by different human development policies. This simple recognition might assist countries in considering the structuring impacts of their economic and social policies, distinguishing between their short-term impacts, seen for instance in citizens' subjective assessments, and long-term impacts, measured by legal institutional initiatives.

Acknowledgements I would like to express my gratitude to Professor Reiner Bruggemann for his generous and helpful comments as well as the valuable suggestions put forward by two anonymous referees.

\section{Declarations}

Conflict of interest Author declares that they have no conflict of interest.

Open Access This article is licensed under a Creative Commons Attribution 4.0 International License, which permits use, sharing, adaptation, distribution and reproduction in any medium or format, as long as you give appropriate credit to the original author(s) and the source, provide a link to the Creative Commons licence, and indicate if changes were made. The images or other third party material in this article are included in the article's Creative Commons licence, unless indicated otherwise in a credit line to the material. If material is not included in the article's Creative Commons licence and your intended use is not permitted by statutory regulation or exceeds the permitted use, you will need to obtain permission directly from the copyright holder. To view a copy of this licence, visit http://creativecommons.org/licenses/by/4.0/.

\section{References}

Alaimo, L., Arcagni, A., Fattore, M. and Maggino, F. (2020) "Synthesis of Multi-Indicator System over time: a Poset-based approach", Social Indicators Research, published online 30 July 2020.

Albo, Y., Lanir, J., \& Rafaeli, S. (2019). A conceptual framework for visualizing composite indicators. Social Indicators Research, 141, 1-30.

Anand, P., Hunter, G., Carter, I., Dowding, K., Guala, F., \& Van Hees, M. (2009). The Development of capability indicators. Journal of Human Development and Capabilities, 10(1), 125-152.

Annoni, P., \& Bruggemann, R. (2009). Exploring partial order of European Countries. Social Indicators Research, 92(3), 471-487.

Aparicio, J., \& Kapelko, M. (2019). Enhancing the measurement of composite indicators of corporate social performance. Social Indicators Research, 144, 807-826.

Arcagni, A., Barbiano di Belgiojoso, E., Fattore, M., \& Rimoldi, S. (2019). Multidimensional analysis of deprivation and fragility patterns of migrants in Lombardy, using partially ordered sets and self-organizing Maps. Social Indicators Research, 141(2), 551-579. 
Arndt, H. W. (1989). Economic development: The history of an idea. University of Chicago Press.

Barclay, M., Dixon-Woods, M., \& Lyratzopoulos, G. (2019). The problem with composite indicators. BMJ Quality \& Safety, 28(4), 338-344.

Brennan, R. (2001). Generalizability theory. Springer.

Bruggemann, R., \& Carlsen, L. (2011). An Improved estimation of averaged ranks of partial orders. MATCH Communications in Mathematical and in Computer Chemistry, 65, 383-414.

Bruggemann, R., \& Patil, G. (2011). Ranking and prioritization for multi-indicator systems. Springer.

Burchardt, T., \& Vizard, P. (2014). Using the Capability Approach to evaluate health and care for individuals and groups in England. In M. Tiwari \& S. Ibrahim (Eds.), The Capability Approach: from theory to practice. Palgrave.

Caperna, G., \& Boccuzzo, G. (2018). Use of poset theory with big datasets: A new proposal applied to the analysis of life satisfaction in Italy. Social Indicators Research, 136, 1071-1088.

Carlsen, L., \& Bruggemann, R. (2019). An analysis of the 'Failed States Index' by partial order methodology. Journal of Social Structure, 14(1), 1-31.

Cherchye, L., Moesen, W., Rogge, N., \& Van Puyenbroeck, T. (2007). "An introduction to 'benefit of the doubt' composite indicators. Social Indicators Research, 82, 111-145.

Comim, F. (2008). Measuring capabilities. In F. Comim, M. Qizilbash, \& S. Alkire (Eds.), The capability approach: Concepts, measures and applications. Cambridge: Cambridge University Press.

Cronbach, L., Gleser, G., Nanda, H., \& Rajaratnam, N. (1972). The Dependability of behavioral measurements. Wiley.

Di Brisco, A., \& Farina, P. (2018). Measuring gender gap from a poset perspective. Social Indicators Research, 136, 1109-1124.

Fattore, M. (2008). Hasse diagrams, poset theory and fuzzy poverty measures. Rivista Internazionale Di Scienze Sociali, Anno, 116(1), 63-75.

Fattore, M. (2016). Partially ordered sets and the measurement of multidimensional ordinal deprivation. Social Indicators Research, 128(2), 835-858.

Fattore, M., \& Arcagni, A. (2018). F-FOD: Fuzzy first order dominance analysis and populations ranking over ordinal multi-indicators system. Social Indicators Research, 144(1), 1-29.

Fattore, M., \& Bruggmann, R. (Eds.). (2017). Partial Order concepts in applied sciences. Springer.

Fattore, M., Maggino, F. and Colombo, E. (2012) "From Composite Indicators to Partial Orders: evaluating socio-economic phenomena through ordinal data”. In: Maggino F, Nuvolati G (eds.) Quality of Life in Italy: research and reflections. Social Indicators Research Series, 48, 41-68.

French, D., Moore, M., \& Canning, D. (2013). Is Human Development Multidimensional? Journal of International Development, 25, 445-455.

Freudenberg, M. (2003) "Composite Indicators of Country performance: a critical assessment". OECD Science, Technology and Industry Working Papers, 2003/16. OECD Publishing. https://doi.org/10. $1787 / 405566708255$

Fukuda-Parr, S. (2011). The Metrics of Human Rights: Complementarities of the Human Development and the Capability Approach. Journal of Human Development and Capabilities, 12(1), 73-89.

Gasper, D., \& Gomez, O. (2014). Evolution of thinking and research on human security and personal security 1994-2013. In K. Malik (Ed.), Safeguarding human progress: Reducing vulnerabilities, building resilience (pp. 365-401). UNDP.

Helliwell, J., Layard, R., Sachs, J., \& De Neve, J. (Eds.). (2020). 2020 World happiness report. Sustainable Development Solutions Network.

Herman, B. (2007). Moral literacy. Harvard University Press.

Hilckmann, A., Bach, V., Bruggemann, R., Ackermann, R., \& Finkbeiner, M. (2017). Partial order analysis of the government dependence of the sustainable development performance in Germany's federal states. In M. Fattore \& R. Bruggemann (Eds.), (2017) Partial Order Concepts in Applied Sciences. Springer.

Ip, E., Chen, S.-H., \& Quandt, S. (2016). Analysis of multiple partially ordered responses to belief items with don't know option. Psychometrika, 81(2), 483-505.

Ivaldi, E., Ciacci, A., \& Soliani, R. (2020). Urban deprivation in Argentina: A poset analysis. Papers in Regional Science, 99(6), 1723-1747.

Kinghorn, P., Robinson, A., \& Smith, R. (2015). Developing a capability-based questionnaire for assessing well-being in patients with chronic pain. Social Indicators Research, 120, 897-916.

Lavagnini, M., \& Mennella, A. (2016). Decent work in Italy: The basic-relations-fairness proposal. Forum for Social Economics, 45(2-3), 193-212.

Levy, S. (1985). Partial order analysis of crime indicators. Social Indicators Research, 16(2), 195-199.

Nussbaum, M. (1990). Love's knowledge. Oxford: Oxford University Press. 
Nussbaum, M. (2011). Creating capabilities: The human development approach. Harvard University Press.

Nussbaum, M. (2018). The monarchy of fear: A philosopher looks at our political crisis. Simon and Schuster Paperbacks.

Piketty, T. (2020). Capital and ideology. The Belknap Press.

Ranis, G. and Stewart, F. (2010) Success and Failure in Human Development, 1970-2007. Human Development Research Paper 2010/10. UNDP

Rosano, A., Mancini, F., \& Solipaca, A. (2009). Poverty in people with disabilities: Indicators from the capability approach. Social Indicators Research, 94(1), 75-82.

Ruiz, F., Gibari, S., Cabello, J., \& Gomez, T. (2020). MRP-WSCI: Multiple reference point based weak and strong composite indicators. Omega, 95, 1-16.

Saltelli, A. (2007). Composite Indicators between analysis and advocacy. Social Indicators Research, 81, $65-77$.

Sen, A. (1970a). Collective choice and social welfare. Holden Day.

Sen, A. (1970b). Interpersonal aggregation and partial comparability. Econometrica, 38(3), 393-409.

Sen, A. (1977). On weights and measures. Informational constraints in social welfare analysis. Econometrica, 45(7), 1539-1572.

Sen, A. (1980). Equality of what? Tanner lectures on human values. Cambridge: Cambridge University Press.

Sen, A. (1985). Commodities and capabilities. Oxford University Press.

Sen, A. (1992). Rationality and freedom. Belknap/Harvard University Press.

Sen, A. (1997). Maximisation and the act of choice. Econometrica, 65, 745-779.

Sen, A. (1999). Development as freedom. Oxford University Press.

Sen, A. (2002). Rationality and freedom. Cambridge, MA and London, England: Harvard University Press.

Sen, A. (2009). The idea of justice. Harvard University Press.

Sen, A. (2017). Collective choice and social welfare (expanded). Penguin Books.

Smirlis, Y. (2020). A trichotomic segmentation approach for estimating composite indicators. Social Indicators Research, 150, 393-410.

Yang, L. (2014). An inventory of composite measures of human progress. occasional paper on methodology. UNDP.

Publisher's Note Springer Nature remains neutral with regard to jurisdictional claims in published maps and institutional affiliations. 